\title{
Profile of anti-IL-5 mAb mepolizumab in the treatment of severe refractory asthma and hypereosinophilic diseases
}

This article was published in the following Dove Press journal:

Journal of Asthma and Allergy

8 October 2015

Number of times this article has been viewed

\section{Francesco Menzella' \\ Mirco Lusuardi² \\ Carla Galeone' \\ Sofia Taddei' \\ Luigi Zucchi'}

'Department of Cardiac-ThoracicVascular and Intensive Care Medicine, Pneumology Unit, Istituto di Ricovero e Cura a Carattere Scientifico- Arcispedale Santa Maria Nuova, Reggio Emilia, Italy; ${ }^{2}$ Unit of Respiratory Rehabilitation, Azienda Unità Sanitaria Locale Reggio Emilia,

S. Sebastiano Hospital, Correggio, Italy

\begin{abstract}
Asthma is a complex disorder frequently associated with a poor symptom control, concomitant morbidity, mortality, and significant health care costs due to lack of compliance or inadequate therapeutic options. Interleukin-5 (IL-5) plays a key role in the pathogenesis of eosinophilic disorders, and in the latest years has become a definite target for treatment. Besides asthma, other hypereosinophilic disorders include the hypereosinophilic syndrome, eosinophilic granulomatosis with polyangiitis, sinonasal polyposis, COPD with eosinophilic airway inflammation, allergic rhinitis, atopic dermatitis, eosinophilic esophagitis. The introduction of mepolizumab, a fully humanized monoclonal antibody that binds to IL-5, may represent a useful therapeutic option to control exacerbations and improve asthma-related quality of life in a subgroup of patients with persistent airway eosinophilia and moderate to severe asthma. Several studies carried out in recent years allow, at present, a careful patient selection for appropriate individualized treatment in severe asthma. Further research is anyway needed in order to better understand the pathogenetic mechanisms of asthma and to find new biomarkers. The high costs of biological agents as compared with standard drugs may be largely offset by increased clinical efficacy and good safety profile in selected patients.
\end{abstract}

Keywords: asthma, mepolizumab, eosinophils, inflammation, IL-5, phenotype

\section{Introduction}

Severe asthma is frequently associated with a suboptimal symptom and exacerbation control, ${ }^{1}$ concomitant morbidity, mortality, and significant health care $\operatorname{costs}^{2}$ due to inadequate therapeutic options and poor adherence, despite the availability of several effective drugs at present. As a consequence, there is an increasing need to identify new molecules able to overcome treatment limitations. Asthma is a complex disorder with many different phenotypes and endotypes ${ }^{3}$ whose definition is based on clinical, inflammatory, or causative factors. The most important pathophysiological mechanism of asthma is represented by airways inflammation, predisposing to exacerbations and bronchial remodeling especially in the absence of regular adequate therapy. ${ }^{4-6} \mathrm{~A}$ typical characteristic of cellular inflammation in asthma is the, sometimes, concomitant presence of eosinophils and neutrophils and their distinct roles in the pathogenesis of the disease. ${ }^{7}$ Eosinophilic asthma is a specific phenotype associated with thickening of the basement membrane and with corticosteroid responsiveness. On the contrary, noneosinophilic asthma, which includes patients with severe disease, is not characterized by basement membrane thickening, and appears to be corticosteroid resistant. ${ }^{8}$

Many researchers have been trying to find drugs to treat bronchial inflammation and prevent the allergic and nonallergic inflammatory cascade responsible for acute relapses of asthma.
Correspondence: Francesco Menzella Department of Cardiac-Thoracic-Vascular and Intensive Care Medicine, Pneumology Unit, IRCCS- Arcispedale Santa Maria Nuova, Viale Risorgimento 56, 42123 Reggio Emilia, Italy

Tel +39052 2296073

Fax +390522296182

Email menzella.francesco@asmn.re.it

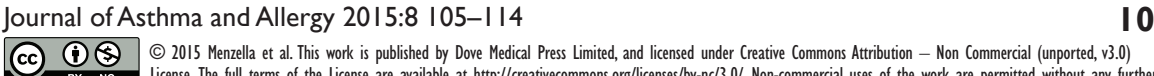

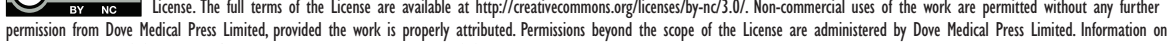

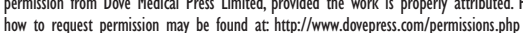


The introduction of omalizumab has represented an innovative tool for therapy, allowing to deal with some unmet needs, in particular for the immunoglobulin E (IgE)-driven phenotype of asthma. ${ }^{9,10}$ Some patients with severe atopic and nonatopic asthma have frequent exacerbations associated with persistent eosinophilic inflammation despite continuous treatment with high-dose inhaled glucocorticoids, with or without oral glucocorticoids. Up to $60 \%$ of the patients present tissue eosinophilia, ${ }^{11}$ whose level is correlated with asthma severity. ${ }^{12}$ Most exacerbations are eosinophilic, while a neutrophilic infiltrate is less common. ${ }^{13}$ Mepolizumab, a humanized monoclonal antibody against interleukin 5 (IL-5) (anti-IL-5 hMoAb), selectively inhibits eosinophilic airway inflammation and induces a significant reduction in severe asthma exacerbations, regardless of IgE levels in blood and atopy. Early studies have demonstrated that mepolizumab does not modify pulmonary function. ${ }^{14,15}$

The aim of this article was to review current literature on mepolizumab, focusing on its applications in the treatment of severe asthma and other hypereosinophilic diseases.

\section{IL-5 and eosinophil role in the inflammatory cascade}

Recruitment, granule maturation, and survival of eosinophils in the airways are promoted by IL-3, granulocyte-macrophage colony stimulating factor (GM-CSF), and especially IL-5, which represents the most important interleukin responsible for eosinophilic airway inflammation in asthmatics. ${ }^{16} \mathrm{IL}-5$ is a 134-amino acid protein that forms a $52 \mathrm{kDa}$ homodimer related to both GM-CSF and IL-3. ${ }^{17-19}$ IL-5 is produced by CD4+ Th2 cells, mast cells, eosinophils, and basophils and is involved in several steps of eosinophil development and function. ${ }^{20}$ It stimulates the final differentiation of activated $\mathrm{B}$ cells into antibody-forming cells and enhances the proliferation and differentiation of eosinophils precursors. ${ }^{21}$

According to some recent experimental studies on murine models, IL-5 seems also to be involved in airway remodeling, since administration of anti-IL-5 in mice blocks almost completely peribronchial and sub-epithelial fibrosis induced by allergen inhalation. ${ }^{22}$

Mature eosinophils circulate in the blood for 6-10 hours ${ }^{23}$ and then migrate to connective tissues to end their life cycle after 8-12 days. The main function of eosinophils is to activate inflammatory immune reactions and to protect the organism from parasites and worms through a number of mechanisms, such as antigen-antibody internalization and presentation, release of proinflammatory mediators, and microrganism killing. These cells express on their surface-specific receptors for the Fc fragment of IgE and are thus able to recognize and bind microorganisms (mainly helminths) opsonized by these antibodies.

Their granules contain not only cytotoxic primary cationic proteins (eosinophil peroxidase, eosinophil cationic protein, major basic protein, eosinophil-derived neurotoxin) but also mediators of allergic reactions, such as histaminase and arylsulfatase. Eosinophils also release IL-5 and leukotrienes that are involved in the pathophysiology of asthma by increasing the secretion of mucus and inducing bronchoconstriction. ${ }^{24}$ The eosinophilia is associated with a wide variety of conditions besides asthma, such as atopic diseases, helminthic infestation, hypersensitivity to drugs, and cancer.

Eosinophils express in particular type I receptor IL-5R $\alpha$, so they respond primarily to IL-5, whose gene is located on chromosome 5 and is close to the genes encoding for IL-3, IL-4, and GM-CSF. The IL-5 receptor includes an $\alpha$ chain and a $\beta c$ chain; the $\alpha$ chain is specific for IL-5, while the $\beta c$ subunit is also recognized by IL-3 and GM-CSF.

IL-5 plays an important role also in basophil and mast cell activity. These cells express several cytokine receptors, such as IL-5R, IL-3R, IL-4R, IL-2Ra, and GM-CSFRa, ${ }^{25-28}$ and produce IL-4 and IL-13. ${ }^{27}$ In addition, after IL-5 and GMCSF stimulation, an increased production of mediators has been observed. Moreover, IL-5 amplifies allergen-induced histamine release from basophils in patients with allergic rhinitis. $^{28}$

The expression of IL-5 is regulated by several transcription factors including GATA3, and its clinical significance has long been associated with numerous diseases including allergic rhinitis and asthma, characterized by a significant increase of eosinophils in blood and airways.

Produced by Th2 lymphocytes and activated mast cells, the main biological role of IL-5 is to control proliferation, differentiation, and activation of eosinophils, representing a functional link between T-cell activation and inflammatory responses mediated by eosinophils.

Eosinophils express a wide spectrum of surface receptors, at least ten different classes, such as CC-chemokine receptor 3 (CCR3), that mediates eosinophil chemotaxis in response to the eotaxins, CCL11, CCL24, and CCL26. ${ }^{29}$ CCR3 can also be activated by CCL5/RANTES, CCL7/ MCP3, CCL/MCP2, and CCL12/MCP5. Eosinophils also express CCR1, the primary receptor for CCL3/MIP1 $\alpha$, CCL5, and the platelet-activating factor receptor.

Other receptors are SIGLEC-8 and SIGLEC-F, cellsurface Ig-like lectins that are members of structurally related carbohydrate-binding protein family. ${ }^{30}$ The functions of 
these proteins are still unknown, but antibodies specific for SIGLEC-8 induce apoptosis of eosinophils.

Pattern-recognition receptors and toll-like receptors are expressed by both human and mouse eosinophils, ${ }^{31}$ although at lower levels than neutrophils and macrophages. These proteins promote eosinophil function in vivo and regulate chemotaxis, adhesion, and survival. ${ }^{32}$

Neutrophils are frequently present in the airways of patients with severe asthma and/or fixed airflow obstruction, and can be detected in airway secretions during severe asthma exacerbations. IL-8 is an important chemoattractant for neutrophils, and its expression by airway smooth muscle cells is upregulated in severe asthmatics. ${ }^{27}$ In the absence of eosinophil chemoattractants, IL-8-stimulated neutrophils help eosinophils to accumulate in asthmatic airways by releasing $\mathrm{O}^{2-}$, MMP-9, LTB4, and PAF. ${ }^{33}$

\section{Therapeutic approach to eosinophilic disorders}

Given the critical role of IL-5 in influencing the biological activities of eosinophils, this molecule and its receptor are a clear target in the treatment of hypereosinophilic diseases. The spectrum of eosinophilic disorders is broad, and includes the hypereosinophilic syndrome (HES), nasal polyposis (NP), COPD with eosinophilic airway inflammation, ${ }^{34}$ allergic rhinitis, atopic dermatitis, eosinophilic esophagitis, eosinophilic granulomatosis with polyangiitis, but especially bronchial asthma (Table 1). ${ }^{35}$

Table I Efficacy and safety of mepolizumab in asthma and other eosinophilic diseases

\begin{tabular}{|c|c|c|}
\hline Disease & Efficacy & Safety profile \\
\hline Asthma & $\begin{array}{l}\text { Mepolizumab reduces peripheral } \\
\text { blood eosinophilia, percentage } \\
\text { of bone marrow eosinophils, airway } \\
\text { eosinophils, and rate of exacerbations } \\
\text { in almost all RCTs. Improvements } \\
\text { in FEVI were found in only two } \\
\text { studies }^{13,36}\end{array}$ & No relevant $\mathrm{AE}$ \\
\hline HES & Primary end points achieved & No relevant $\mathrm{AE}$ \\
\hline EGBPA & Primary end points achieved & No relevant $\mathrm{AE}$ \\
\hline $\begin{array}{l}\text { Eosinophilic } \\
\text { esophagitis }\end{array}$ & Primary end points not achieved & No relevant $\mathrm{AE}$ \\
\hline $\begin{array}{l}\text { Nasal } \\
\text { polyposis }\end{array}$ & Primary end points achieved & No relevant $\mathrm{AE}$ \\
\hline $\begin{array}{l}\text { Atopic } \\
\text { dermatitis }\end{array}$ & Primary end points not achieved & No relevant $\mathrm{AE}$ \\
\hline COPD & Ongoing RCTs & $\begin{array}{l}\text { No data available } \\
\text { at the time }\end{array}$ \\
\hline
\end{tabular}

Abbreviations: HES, hypereosinophilic syndrome; EGBPA, eosinophilic granulomatosis with polyangiitis; $\mathrm{AE}$, adverse event; $\mathrm{RCT}$ s, randomized clinical trials; FEVI, forced expiratory volume in I second.
Several randomized clinical trials (RCTs) have been performed, and many others are currently in various stages of development with regard to anti-IL-5 (mepolizumab, reslizumab) or IL-5R $\alpha$ (benralizumab) monoclonal antibodies. All the clinical trials conducted so far showed a reduction of eosinophils in peripheral blood and induced sputum but a large variability has been found in clinical results (Table 1). ${ }^{14,36-41}$

\section{Early studies and controversies on mepolizumab for asthma}

Mepolizumab (SB-240563, Bosatria ${ }^{\circledR}$; GlaxoSmithKline, Brentford, UK) was the first anti-IL-5 molecule designed and tested in RCTs for eosinophilic allergic asthma. It is a humanized monoclonal ${ }^{42} \mathrm{~N}$-glycosylated IgG1 kappa antibody able to inhibit IL-5 with both high specificity (half maximal inhibitory concentration $<1 \mathrm{nM}$ ) and affinity (kilodalton $=4.2 \mathrm{pM}$ ), thus preventing its binding to the alpha chain of the IL-5 receptor complex expressed on the eosinophil cell surface. ${ }^{43}$ Mepolizumab is formed by two light chains and two heavy chains connected by a disulfide bridge with a molecular weight of $49 \mathrm{kDa}$ (Figure 1). ${ }^{44-47}$

Hart et $\mathrm{al}^{47}$ carried out a preclinical study on the pharmacological activity and safety of mepolizumab in Naive and Ascaris suum-sensitive cynomolgus monkeys. Single intravenous (IV) dose of mepolizumab significantly reduced blood eosinophilia, eosinophil migration into airways, and levels of RANTES and IL-6 in lungs for 6 weeks. However, mepolizumab did not affect acute bronchoconstrictive responses. Monthly doses of mepolizumab $>5 \mathrm{mg} / \mathrm{kg}$ caused an $80 \%-100 \%$ decrease in blood and bronchoalveolar lavage eosinophils lasting 2 months after administration; there was no effect on eosinophil precursors in bone marrow after 6 months of treatment. The study demonstrated the safety of this drug in monkeys with a long-term reduction in circulating and tissue-resident eosinophils, which correlated with mepolizumab plasma concentrations. In one of the first studies on humans, Leckie et al tested mepolizumab in a small group of 24 patients with mild atopic asthma. ${ }^{14}$ The study had the aim of evaluating efficacy of a single IV dose of mepolizumab in the reduction of eosinophilia in sputum, airway hyperresponsiveness (AHR), and late response to inhaled allergens. Study results showed a reduction of both blood and sputum eosinophils after 4 and 16 weeks of treatment: blood eosinophil level decreased from $0.25 \times 10^{9} / \mathrm{L}$ in the placebo group to $0.04 \times 10^{9} / \mathrm{L}$ in the $10 \mathrm{mg} / \mathrm{kg}$ group $(P<0.0001)$. After inhaled allergen challenge, sputum eosinophils were $12.2 \%$ in the placebo group and $0.9 \%$ $(P=0.0076)$ in the $10 \mathrm{mg} / \mathrm{kg}$ group, with a persistent effect 


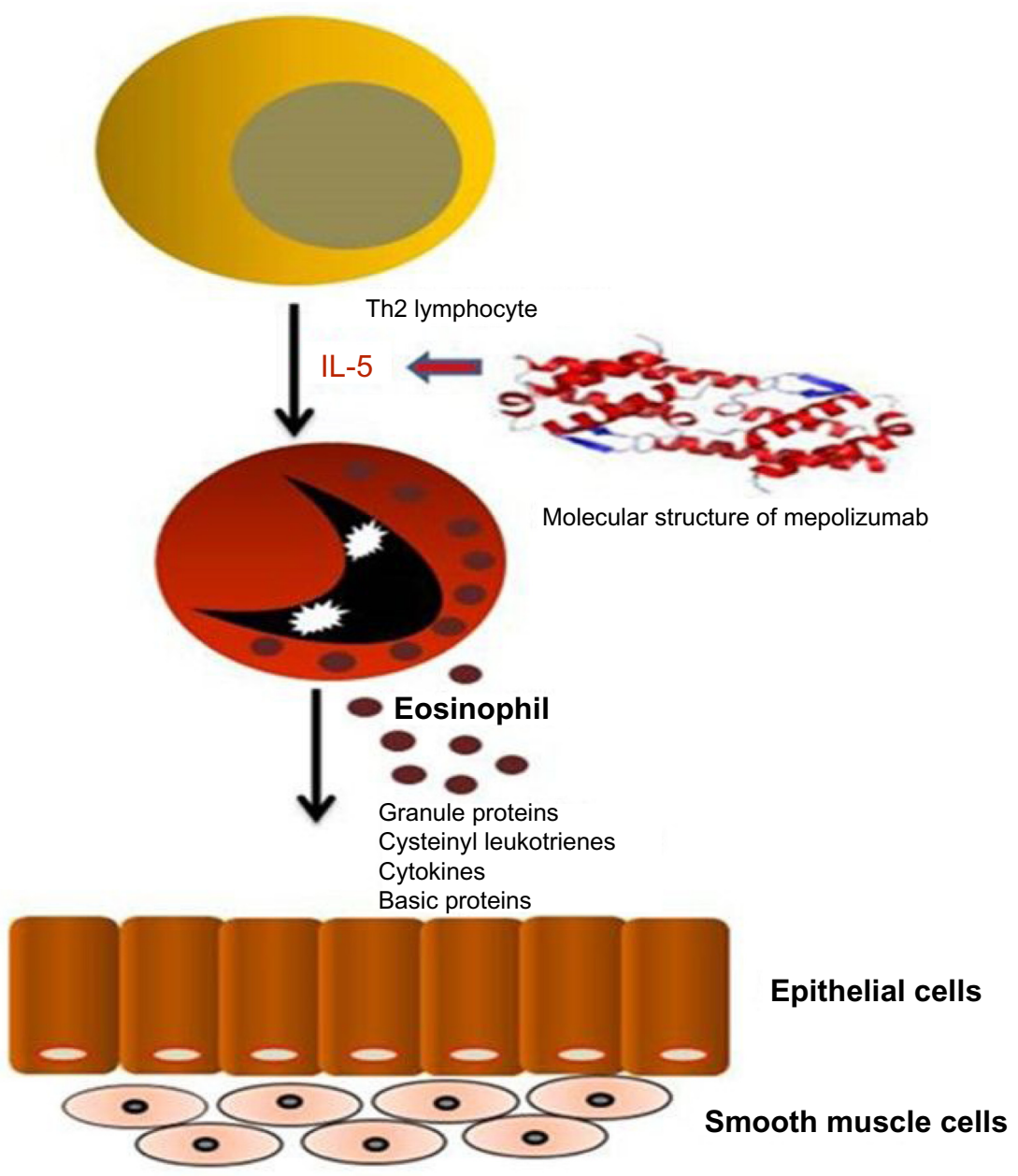

Figure I Interaction between Th2 lymphocytes and eosinophils, and molecular structure of mepolizumab with its therapeutic target. Abbreviation: IL, interleukin.

at day 30 after the dose. There were no effects on AHR and late response to inhaled allergens.

Flood-Page et $\mathrm{al}^{15}$ evaluated in a fashion randomized, doubleblind, parallel-group study the effect of three $750 \mathrm{mg}$ IV doses of mepolizumab or placebo in a group of 24 mild asthma patients. Mepolizumab produced a median decrease from baseline of $55 \%$ for airway eosinophils, $52 \%$ for bone marrow eosinophils, and $100 \%$ for blood eosinophils, without appreciable effect on bronchial mucosa staining for eosinophil major basic protein. There were no significant changes in clinical outcomes (AHR, forced expiratory volume in 1 second [FEV1], and peak expiratory flow $[\mathrm{PEF}]$ recordings) between the mepolizumab and placebo groups. Anti-IL-5 treatment reduced but did not deplete airway or bone marrow eosinophils.

\section{Anti-IL-5 mAbs for asthma: from early clinical failure to evidence of efficacy}

The first mepolizumab study produced contradictory results, and several authors questioned the efficacy of this new molecule on asthma treatment. ${ }^{15,48}$ As a matter of fact, no significant data were found in terms of AHR, PEF, and FEV1 despite a remarkable reduction of airway and blood eosinophilia ${ }^{14,15}$ in fact, anti-IL-5 produced a median decrease of $55 \%$ for airway eosinophils, $52 \%$ for bone marrow eosinophils $(P=0.003)$, and $100 \%$ for blood eosinophils $(P=0.02)$. Another RCT had the aim of investigating the effect of three IV infusions of mepolizumab, 250 or $750 \mathrm{mg}$ at monthly intervals, on clinical outcome measures in 362 patients with asthma experiencing persistent symptoms despite inhaled corticosteroid therapy. Mepolizumab was associated with a significant reduction in blood and sputum eosinophils in both treatment groups, but an incorrect selection of the sample did not take into due consideration the level of airways eosinophilic inflammation and did not allow statistically significant changes to be found in any of the clinical end points measured. There was a trend for decrease in exacerbation rates in the mepolizumab $750 \mathrm{mg}$ treatment group, but it was not statistically significant ( $P=0.0065)$; therefore, the treatment did not appear to add clinical benefit. ${ }^{36}$ 
On the contrary, two subsequent studies demonstrated mepolizumab efficacy in the control of asthma. The first one was a study on 61 subjects who had refractory eosinophilic asthma and a history of recurrent severe exacerbations. ${ }^{37}$ Patients received IV infusions of either mepolizumab or placebo at monthly intervals for 1 year. Mepolizumab was associated with significantly fewer severe exacerbations than placebo (2.0 vs 3.4 mean exacerbations per patient), with a significant improvement in the Asthma Quality of Life Questionnaire AQLQ score and a decrease of eosinophil counts in the blood and sputum, $P<0.001$ and $P=0.002$, respectively. However, there were no significant differences between the two groups with respect to symptoms, postbronchodilator FEV1, or AHR. The second report was another study involving patients with persistent sputum eosinophilia and symptoms despite prednisone treatment. ${ }^{38}$ Nine patients were assigned to receive mepolizumab, administered in five monthly IV infusions of $750 \mathrm{mg}$, and eleven patients to placebo. There were 12 asthma exacerbations in ten patients who received placebo, while only one patient who received mepolizumab had an asthma exacerbation. The use of mepolizumab was associated with a significant decrease in the number of sputum and blood eosinophils $(P=0.002)$. Moreover, subjects who received mepolizumab were able to reduce their prednisone dose and improvements in eosinophil numbers, asthma control, and FEV1 were maintained for 8 weeks after the latest infusion.

A conclusive research was the DREAM trial, ${ }^{39}$ a large multicentre, double-blind, placebo-controlled study recruiting 621 patients with a history of recurrent severe asthma exacerbations and signs of eosinophilic inflammation. They were randomly assigned to receive one of three doses of IV mepolizumab ( $75 \mathrm{mg}, 250 \mathrm{mg}$, or $750 \mathrm{mg}$ ) or matched placebo $(100 \mathrm{~mL} 0.9 \% \mathrm{NaCl})$. Mepolizumab was demonstrated to significantly reduce the number of asthma exacerbations in patients with severe eosinophilic asthma compared with placebo. It was observed that $75 \mathrm{mg}, 250$ $\mathrm{mg}$, and $750 \mathrm{mg}$ mepolizumab reduced the rate of clinically significant exacerbations per patient per year by $48 \%$ $(P<0.001), 39 \%(P=0.005)$, and 52\% $(P<0.001)$, respectively. Additionally, each dose of treatment lowered blood and sputum eosinophil counts $(P<0.0001)$ and was well tolerated for 12 months, despite a small effect on FEV1, AQLQ, and Asthma Control Questionnaire (ACQ) scores compared with the placebo group.

These studies have represented an important progress in the selection of the most appropriate treatment for the subgroup(s) of patients affected by severe asthma with frequent exacerbations and persistent eosinophilia, which may be approximately $40 \%$ of severe asthmatics. ${ }^{49} \mathrm{~A}$ post hoc analysis of the DREAM trial tried to assess the effect of treatment with mepolizumab on the frequency of exacerbations in the atopic and non-atopic subgroups, seasonal patterns of response by subgroup, and the changes in lung function and exhaled nitric oxide fraction according to subgroup..$^{50}$ Interestingly, the reduction in exacerbations with mepolizumab treatment was unaffected by season or atopy/IgE levels. Later, a supervised cluster analysis with recursive partitioning approach was applied to data of DREAM study to identify characteristics that maximized the differences among subgroups. ${ }^{51}$ Three predictors were identified in four primary clusters: blood eosinophils, airway reversibility, and body mass index. The reduction in exacerbations and significant therapeutic benefit was larger in patients with eosinophilic inflammation who received mepolizumab, confirming the necessity of this condition as a response predictor.

Another recent work compared the efficacy responses in the oral corticosteroids (OCS)-dependent group from the DREAM study with the non-OCS-dependent subgroup. Mepolizumab reduced the peripheral eosinophils and was effective at reducing exacerbation rates in the non-OCS and OCS groups during the 52-week treatment period with a greater reduction noted in the OCS group. At study entry, peripheral eosinophils level was $\geq 300$ cells $/ \mathrm{mL}$ in the previous 12 months; after active treatment, a reduction of $71 \%$ in non-OCS-dependent group and 65\% in OCS-dependent group was observed; $P=0.136$ for non-OCS versus OCS groups. The exacerbation rate/year was 1.90 for placebo and 1.07 for mepolizumab in the non-OCS-dependent group, and 3.12 for placebo and 1.54 for mepolizumab in the OCS-dependent group, with a rate ratio of 0.56 and 0.49 , respectively $(P=0.503)$. These results showed that mepolizumab treatment reduces peripheral eosinophils and exacerbation risk both in OCS-dependent and non-OCSdependent group. ${ }^{52}$

In the subsequent MENSA trial, 576 patients were selected with recurrent asthma exacerbations and eosinophilic inflammation despite high doses of inhaled glucocorticoids in one of three study groups. ${ }^{53}$ Patients were assigned to receive treatment with mepolizumab, administered as either a $75 \mathrm{mg}$ IV dose or a $100 \mathrm{mg}$ subcutaneous (SC) dose, or placebo every 4 weeks for 32 weeks. The primary end point was the rate of exacerbation, secondary outcomes were FEV1, scores on the St George's Respiratory Questionnaire (SGRQ), and the five-item Asthma Control Questionnaire (ACQ-5). The rate of exacerbations was reduced by $47 \%$ among patients receiving IV dose and by $53 \%$ among those receiving SC dose. At the 
end of the study, the mean increase from baseline in FEV1 was $100 \mathrm{~mL}$ greater in patients receiving IV mepolizumab than in those receiving placebo and $98 \mathrm{~mL}$ greater in patients receiving SC mepolizumab than in placebo group. There were also significant improvements in the SGRQ and ACQ-5 scores in the IV and SC mepolizumab groups than in the placebo group, with a safety profile of mepolizumab comparable to placebo. Mepolizumab decreased the eosinophil counts by week 4 of treatment (with reductions of $83 \%$ in the IV group and $86 \%$ in the SC group), and variations were maintained during the study. All these findings confirmed the efficacy of mepolizumab administered either intravenously or subcutaneously in terms of reduction of asthma exacerbations but, unlike other studies, all the clinical measures of asthma control were also improved.

In a 12-month follow-up analysis following the study of Haldar et $a 1,{ }^{37}$ the authors reported the changes that occurred after stopping mepolizumab therapy. Cessation of treatment was associated with an early rise in the blood eosinophils continuing to baseline levels over 6 months. The frequency of severe exacerbations increased significantly at 3 to 6 months after stopping mepolizumab and the worsening of asthma control was anticipated by a rise in sputum and blood eosinophils. ${ }^{54}$

A Phase III, multicenter, placebo-controlled, doubleblind, parallel-group study is currently underway and is recruiting 780 patients with severe eosinophilic asthma to evaluate the safety and efficacy of mepolizumab adjunctive therapy $^{55}$ on markers of disease control. Primary outcome measure is mean change from baseline in SGRQ score at week 24 . Secondary outcome measures are the mean change from baseline in pre-bronchodilator FEV1, percentage of participants achieving a 4-point or greater reduction from baseline in SGRQ score, and mean change from baseline in ACQ-5 score at week 24. The overall intent of this RCT is to fully explore the impact of mepolizumab on health-related quality of life and other measures of asthma control, including lung function (Table 2).

Despite controversial evidence of clinical efficacy, the first trials in particular being less favorable than the latest more positive ones, all the studies quoted earlier demonstrated a positive effect of mepolizumab on blood eosinophil counts. ${ }^{14,36-41,53}$ As a matter of fact, a pooled analysis from seven studies on a total of 1,131 patients showed that IV or SC administration of mepolizumab was associated with a significant reduction in blood eosinophils compared to placebo (mean deviation: $-0.29 \times 10^{9} / \mathrm{L}, 95 \%$ confidence interval $[\mathrm{CI}]:-0.44$ to $\left.-0.14 \times 10^{9} / \mathrm{L}, P=0.0001\right)$. Also, data demonstrated a

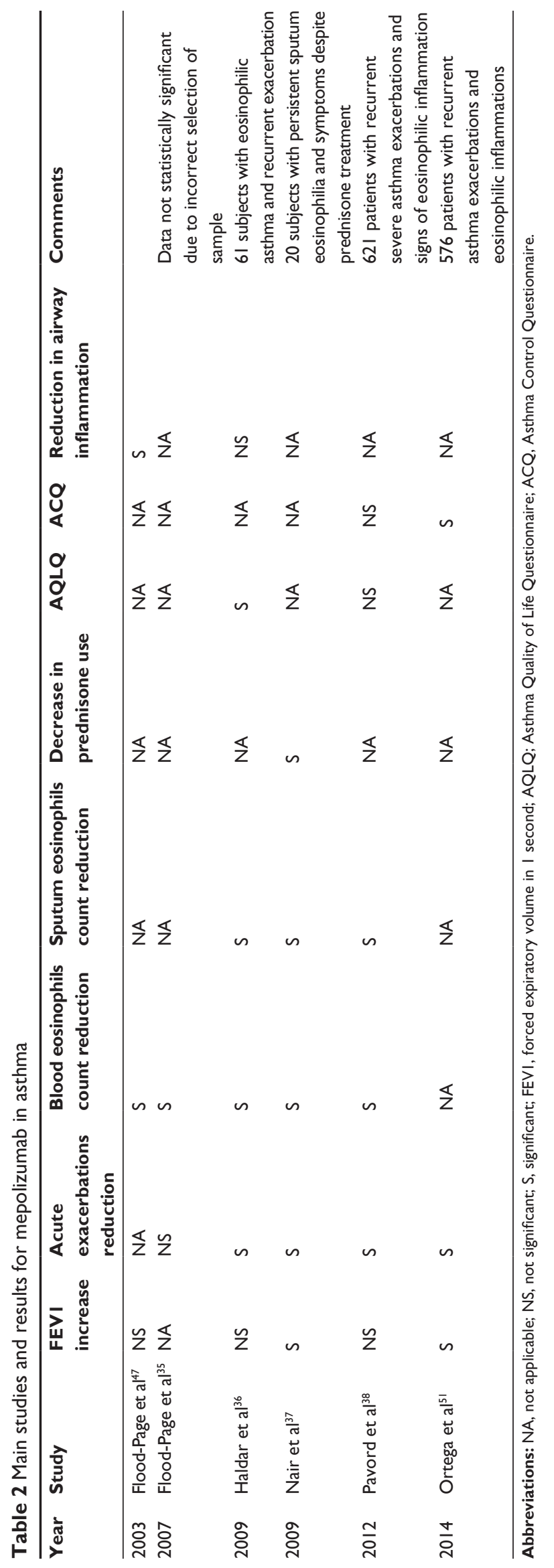


significant reduction for the percentage of sputum eosinophils, with a mean difference of $-6.05 \%(P=0.0003){ }^{56}$

Finally, an unusual Phase II, double-blind, placebocontrolled study evaluated the effect of one IV dose of benralizumab, added to current standard asthma medication, on recurrence (asthma exacerbations and/or hospitalization for acute asthma) after an emergency department (ED) visit for asthma exacerbation. ${ }^{57}$ Patients were stratified by baseline eosinophil count of less than or equal to 450 or greater than 450 cells $/ \mu \mathrm{L}$. Administration of one dose of benralizumab resulted in a long-lasting reduction of eosinophils and in the rate and severity of exacerbations in subjects who presented to the ED with severe asthma exacerbation and were poorly responsive to standard therapy. This study may represent a further step to identify patients suitable for anti-IL-5 mAbs treatment, even in an emergency setting so far not considered.

\section{Mepolizumab in other hypereosinophilic diseases}

Whenever the presence of systemic eosinophilic inflammation is a clinically relevant finding, it is intuitive to think that blocking IL-5 or its receptor could be a promising strategy for treatment. Therefore, not only asthma but also other, sometimes very severe, eosinophil-related disorders may represent a potential target for IL-5 inhibition. These conditions include HES and atopic dermatitis (AD), eosinophilic granulomatosis with polyangiitis, eosinophilic esophagitis (EoE), and NP. In 2004, Garrett et al ${ }^{58}$ published an open-label trial of antiIL-5 in which three IV doses were administered at 4-week intervals to four patients with HES (defined by peripheral blood and/or tissue eosinophilia). The effects of treatment on safety, eosinophil levels (in peripheral blood and/or tissue), pulmonary function, and quality of life were measured over a 28-week period. Anti-IL-5 was well tolerated in all patients and lowered peripheral blood eosinophil counts, which had remained persistently high despite systemic glucocorticoid therapy. The decline in circulating eosinophil counts was sustained for at least 12 weeks after the last dose of anti-IL-5. In addition, anti-IL-5 improved clinical and quality of life measurements. This study suggested a significant therapeutic potential of mepolizumab for HES. A study by Rothenberg et $\mathrm{al}^{59}$ showed that treatment with mepolizumab had a positive corticosteroid-sparing effect in patients negative for Fip1-like1-platelet-derived growth factor receptor (FIP1L1PDGFRA) fusion gene affected by the HES, confirming the effectiveness of the drug for this disease.

Since tissue and blood eosinophils in $\mathrm{AD}$ are more activated than in other eosinophilic disorders ${ }^{60}$ and peripheral blood eosinophils of AD patients show a significantly delayed programmed cell death. ${ }^{61}$ Mepolizumab was earlier considered a potential treatment for this disease. ${ }^{62} \mathrm{~A}$ randomized double-blind, placebo-controlled, parallel group study enrolled 18 patients with AD to receive two single IV doses of $750 \mathrm{mg}$ mepolizumab and 22 to receive placebo treatment. Peripheral blood eosinophil counts were significantly reduced in the treatment group compared with placebo but no clinical success was reached by the physician's global assessment, objective scoring atopic dermatitis (SCORAD), and itch scoring. ${ }^{6}$

In EGPA, formerly known as the Churg-Strauss Syndrome, mepolizumab was used for remission induction in an open-label study of ten patients with refractory or relapsing EGPA; in eight of these subjects a remission was observed, allowing a reduction of OCS. ${ }^{64} \mathrm{~A}$ later case series that studied seven patients with EGBPA, treated with only four IV doses of mepolizumab, showed a reduction of OCS dose in all patients with a stability of symptoms and an optimal safety profile during the study. ${ }^{65}$

In an interesting study, authors investigated whether mepolizumab treatment reduced esophageal mast cell accumulation in 43 pediatric EoE biopsy specimens from a previous randomized anti-IL-5 trial. Forty percent of the patients responded to anti-IL-5 (defined as $<15$ eosinophils per high-power field following mepolizumab therapy), and $77 \%$ of all subjects had significantly fewer mast cells, IL-9+ cells, and mast cell-eosinophil couplets in the esophageal epithelium. ${ }^{66}$

Anti-IL-5 was studied in two subsequent RCTs, ie, in pediatric and adult patients, respectively. ${ }^{67-68} \mathrm{~A}$ mild-tomoderate improvement in eosinophils counts was observed, but mepolizumab did not improve symptoms compared to placebo.

Finally, 30 patients with severe NP (grade 3 or 4 or recurrent after surgery) refractory to corticosteroids were randomized to receive either two single IV injections of $750 \mathrm{mg}$ mepolizumab or placebo. ${ }^{69}$ The primary outcome of this study was the reduction in NP score at 8 weeks after the first dosing and secondary outcomes included changes in CT scan scores and functional assessments, such as nasal peak inspiratory flow or symptom scores. Mepolizumab produced a significant reduction in total polyp score in 12 of 20 patients, as confirmed by computed tomography (CT) scan evaluations.

\section{Future developments: COPD}

In severe COPD patients, the eosinophil-predominant phenotype is associated with an increased risk of exacerbations 
and oral corticosteroid treatment. Two Phase III RCTs are currently in progress to evaluate the efficacy and safety of mepolizumab as an adjunctive therapy for adults affected by COPD with eosinophil-predominant phenotype..$^{70,71}$ These studies will enroll approximately 1,500 patients at high risk of exacerbations despite standard care. The primary end points of the two studies are the frequency of exacerbations and the decrease of sputum eosinophils from baseline.

\section{Safety profile}

Available literature data demonstrate that anti-IL-5 treatment is safe for clinical use. It was very well tolerated in all clinical trials. Anti-mepolizumab neutralizing antibodies were detected in fewer than $2 \%$ of cases in two studies. ${ }^{36,72}$ In large trials, the number of adverse events were superimposable to placebo. ${ }^{39,50}$

\section{Conclusion}

In recent years, a remarkable progress in the scientific knowledge about pathogenetic mechanisms and therapeutic strategies for asthma has had only a partial impact on our ability to improve clinical outcomes. Asthma in fact is a very heterogeneous disease and only an accurate identification of the "phenotype", through anatomical, clinical, functional, and biological evaluations can allow a correct definition of the clinical and therapeutic patient profile. The present lack of validated biomarkers makes the physician's job even harder, since IL-5 may not be the only player of persistent airway eosinophilia and may also involve other immune cells and Th2- cytokine such as Il-13. Despite high doses of inhaled corticosteroids or oral corticosteroids, $5 \%$ of asthmatics have severe symptoms, enhanced airway remodeling, frequent exacerbations, and a greater risk to die from asthma. A subgroup $(20 \%-40 \%)$ of these patients has persistent airway eosinophilia and frequent exacerbations. ${ }^{73}$ A neutrophilic inflammation, which persists even under full corticosteroid therapy, may contribute in part to the manifestations of severe asthma, through the control of eosinophilic inflammation. ${ }^{74}$ The identification of an "eosinophilic phenotype", supported by several and sometimes controversial studies, would allow to select a subgroup of potential mepolizumab responders, which may overcome the problem of poor response to OCS. Several studies did not show a significant improvement in lung function, probably due to limited efficacy in removing tissue eosinophils and proinflammatory mediators $;{ }^{15}$ however, mepolizumab can be a promising therapeutic option in selected subjects with persistent airway eosinophilia for the positive results obtained in clinical outcome measures, such as decrease in exacerbation rate, quality of life improvement, and good safety profile. An appropriate patient selection is therefore essential to avoid treatment failure, because several studies confirm that in a specific subgroup of patients, eosinophils play an important role in exacerbations and mepolizumab therapy may have clinical benefit. However, when eosinophilia is not present, or even in some patients with eosinophilic asthma, mepolizumab has no clinical effects.

Biological therapies in asthma are far more expensive than standard drugs. ${ }^{75}$ While manufacturer has not given any hint as to the price of mepolizumab, analysts estimate a cost from $\$ 10,000$ to $\$ 15,000$ per patient per year of treatment. ${ }^{76}$ Owing to its clinical efficacy and safety profile in selected subsets of severe patients at high risk for hospitalization and fatal asthma, the treatment by using this drug might prove to be a cost-effective one.

\section{Disclosure}

The authors report no conflicts of interest in this work.

\section{References}

1. Accordini S, Corsico AG, Braggion M, et al. The cost of persistent asthma in Europe: an international population-based study in adults. Int Arch Allergy Immunol. 2013;160(1):93-101.

2. Rabe KF, Adachi M, Lai CK, et al. Worldwide severity and control of asthma in children and adults: the global asthma insights and reality surveys. J Allergy Clin Immunol. 2004;114(1):40-47.

3. Wenzel S. Severe asthma: from characteristics to phenotypes to endotypes. Clin Exp Allergy. 2012;42(5):650-658.

4. Manuyakorn W, Howarth PH, Holgate ST. Airway remodelling in asthma and novel therapy. Asian Pac J Allergy Immunol. 2013;31(1): 3-108.

5. Schuijs MJ, Willart MA, Hammad H, Lambrecht BN. Cytokine targets in airway inflammation. Lung damage and airway remodelling in severe asthma. Curr Opin Pharmacol. 2013;13(3):351-361.

6. Brightling CE, Gupta S, Gonem S, Siddiqui S. Lung damage and airway remodelling in severe asthma. Clin Exp Allergy. 2012;42(5):638-649.

7. Fahy JV. Eosinophilic and neutrophilic inflammation in asthma: insights from clinical studies. Proc Am Thorac Soc. 2009;16(3):256-259.

8. Pepe C, Foley S, Shannon J, et al. Differences in airway remodeling between subjects with severe and moderate asthma. J Allergy Clin Immunol. 2005;116:544-549.

9. Humbert M, Beasley R, Ayres J, et al. Benefits of omalizumab as add-on therapy in patients with severe persistent asthma who are inadequately controlled despite best available therapy (GINA 2002 step 4 treatment): INNOVATE. Allergy. 2005;60(3):309-316.

10. Normansell R, Walker S, Milan SJ, et al. Omalizumab for asthma in adults and children. Cochrane Database Syst Rev. 2014;1:CD003559.

11. Zhang JY, Wenzel SE. Tissue and BAL based biomarkers in asthma. Immunol Allergy Clin North Am. 2007;27:623-632.

12. Bousquet J, Chanez P, Lacoste JY, et al. Eosinophilic inflammation in asthma. N Engl J Med. 1990;323:1033-1039.

13. Turner MO, Hussack P, Sears MR, et al. Exacerbations of asthma without sputum eosinophilia. Thorax 1995;50:1057-1061.

14. Leckie MJ, ten Brinke A, Khan J, et al. Effects of an interleukin-5 blocking monoclonal antibody on eosinophils, airway hyper-responsiveness, and the late asthmatic response. Lancet 2000;356:2144-2148. 
15. Flood-Page PT, Menzies-Gow AN, Kay AB, Robinson DS. Eosinophil's role remains uncertain as anti-interleukin-5 only partially depletes numbers in asthmatic airway. Am J Respir Crit Care Med. 2003;167(2): 199-204.

16. Uhm TG, Kim BS, Chung IY. Eosinophil development, regulation of eosinophil-specific genes, and role of eosinophils in the pathogenesis of asthma. Allergy Asthma Immunol Res. 2012;4(2):68-79.

17. McKinnon M, Bank M, Solari R, Robinson G. Interleukin-5 and the interleukin receptor: targets for drug discovery in asthma. In: Sanderson CJ, editor. Interleukin-5: From molecule to Drug Target for Asthma. New York: Marcel Dekker, Inc.;1999:299-320.

18. Menzies-Gow A, Flood-Page P, Sehmi R, et al. Anti-IL-5 (mepolizumab) therapy induces bone marrow eosinophil maturational arrest and decreases eosinophil progenitors in the bronchial mucosa of atopic asthmatics. J Allergy Clin Immunol. 2003;111(4):714-719.

19. Wells TN, Graber P, Proudfoot AE, et al. The three-dimensional structure of human interleukin-5 at 2.4-angstroms resolution: implication for the structures of other cytokines. Ann NY Acad Sci. 1994;28(725):118-127.

20. Takatsu K, Nakajima H. IL-5 and eosinophilia. Curr Opin Immunol. 2008;20:288-294.

21. Kouro T, Takatsu K. IL-5- and eosinophil-mediated inflammation: from discovery to therapy. Int Immunol. 2009;21(12):1303-1309.

22. Tanaka H, Komai M, Nagao K, et al. Role of interleukin-5 and eosinophils in allergen-induced airway remodeling in mice. Am J Respir Cell Mol Biol. 2004;31:62.

23. Becchetti E, Bani D, Baroni T. Istologia Umana. Napoli: IdelsonGnocchi. 2011:393-394. ISBN 9788879475419.

24. Rosenberg HF, Dyer KD, Foster PS. Eosinophils: changing perspectives in health and disease. Nat Rev Immunol. 2013;13(1):9-22.

25. Valent P. The phenotype of human eosinophils, basophils, and mast cells. J Allergy Clin Immunol. 1994;94:1177-1183.

26. Toba K, Koike T, Shibata A, et al. Novel technique for the direct flow cytofluorometric analysis of human basophils in unseparated blood and bone marrow, and the characterization of phenotype and peroxidase of human basophils. Cytometry 1999;35:249-259.

27. Dahinen CA, Rihs S, Ochsensberger B. Regulation of cytokine expression by human blood basophils. Int Arch Allergy Immunol. 1997;113:134-137

28. Kowal K, Nolte H, Skov PS, et al. Effect of allergen-specific immunotherapy on recombinant human interleukin 3-mediated amplification of allergen-induced basophil histamine release. Allergy Asthma Proc. 2005;26:456-462.

29. Lloyd CM, Rankin SM. Chemokines in allergic airway disease. Curr Opin Pharmacol. 2003;3:443-448.

30. Bochner BS. Siglec-8 on human eosinophils and mast cells, and Siglec-F on murine eosinophils, are functionally related inhibitory receptors. Clin Exp Allergy. 2009;39:317-324.

31. Kvarnhammar AM, Cardell LO. Pattern recognition receptors in human eosinophils. Immunology 2012;136:11-20.

32. Månsson A, Cardell LO. Role of atopic status in Toll-like receptor (TLR)7- and TLR9-mediated activation of human eosinophils. J Leukoc Biol. 2009;85:719-727.

33. Nakagome K, Matsushita S, Nagata M. Neutrophilic inflammation in severe asthma. Int Arch Allergy Immunol. 2012;158(1):96-102.

34. Bafadhel M, McCormick M, Saha S, et al. Profiling of sputum inflammatory mediators in asthma and chronic obstructive pulmonary disease. Respiration 2012;83(1):36-44.

35. Menzella F, Lusuardi M, Galeone C, Zucchi L. Tailored therapy for severe asthma. Multidiscip Respir Med. 2015;10(1):1

36. Flood-Page P, Swenson C, Faiferman I, et al. A study to evaluate safety and efficacy of mepolizumab in patients with moderate persistent asthma. Am J Respir Crit Care Med. 2007;176:1062-1071.

37. Haldar P, Brightling CE, Hargadon B, et al. Mepolizumab and exacerbations of refractory eosinophilic asthma. N Engl J Med. 2009;360:973-984.

38. Nair P, Pizzichini MM, Kjarsgaard M, et al. Mepolizumab for prednisone-dependent asthma with sputum eosinophilia. $N$ Engl J Med. 2009;360:985-993.
39. Pavord ID, Korn S, Howarth P, et al. Mepolizumab for severe eosinophilic asthma (DREAM): a multicentre, double-blind, placebocontrolled trial. Lancet 2012;380:651-659.

40. Castro M, Zangrilli J, Wechsler ME, et al. Reslizumab for inadequately controlled asthma with elevated blood eosinophil counts: results from two multicentre, parallel, double-blind, randomised, placebo-controlled, phase 3 trials. Lancet Respir Med. 2015;3(5):355-366.

41. Lim HF, Nair P. Efficacy and safety of reslizumab in patients with moderate to severe eosinophilic asthma. Expert Rev Respir Med. 2015;9(2):135-142.

42. Zia-Amirhosseini P, Minthorn E, Benincosa LJ, et al. Pharmacokinetics and pharmacodynamics of SB-240563, a humanized monoclonal antibody directed to human interleukin-5, in monkeys. J Pharmacol Exp Ther. 1999;291(3):1060-1067.

43. European Medicines Agency. Withdrawal Assessment Report for Bosatria. London, UK: European Medicines Agency; 2009. Doc. Ref: EMEA/454803/2009.

44. LopezAF, Sanderson CJ, Gamble JR, Campbell HD, Young IG, Vadas MA. Recombinant human interleukin 5 is a selective activator of human eosinophil function. J Exp Med. 1988;167(1):219-224.

45. Ohnishi T, Sur S, Collins DS, Fish JE, Gleich GJ, Peters SP. Eosinophil survival activity identified as interleukin- 5 is associated with eosinophil recruitment and degranulation and lung injury twenty-four hours after segmental antigen lung challenge. J Allergy Clin Immunol. 1993; 92(4):607-615.

46. Clutterbuck EJ, Sanderson CJ. Regulation of human eosinophil precursor production by cytokines: a comparison of recombinant human interleukin-1 (rhIL-1), rhIL-3, rhIL-5, rhIL-6, and rh granulocyte-macrophage colony-stimulating factor. Blood 1990;75(9): 1774-1779.

47. Hart TK, Cook RM, Zia-Amirhosseini P, et al. Preclinical efficacy and safety of mepolizumab (SB-240563), a humanized monoclonal antibody to IL-5, in cynomolgus monkeys. J Allergy Clin Immunol. $2001 ; 108(2): 250-257$

48. Wenzel SE. Eosinophils in asthma - closing the loop or opening the door? N Engl J Med. 2009;360(10):1026-1028.

49. Simpson JL, Scott R, Boyle MJ, Gibson PG. Inflammatory subtypes in asthma: assessment and identification using induced sputum. Respirology. 2006;11:54-61.

50. Ortega H, Chupp G, Bardin P, et al. The role of mepolizumab in atopic and nonatopic severe asthma with persistent eosinophilia. Eur Respir J. 2014;44(1):239-241.

51. Ortega H, Li H, Suruki R, Albers F, Gordon D, Yancey S. Cluster analysis and characterization of response to mepolizumab. A step closer to personalized medicine for patients with severe asthma. Ann Am Thorac Soc. 2014;11(7):1011-1017.

52. Prazma CM, Wenzel S, Barnes N, Douglass JA, Hartley BF, Ortega H. Characterisation of an OCS-dependent severe asthma population treated with mepolizumab. Thorax. 2014;69(12):1141-1142.

53. Ortega HG, Liu MC, Pavord ID, et al. Mepolizumab treatment in patients with severe eosinophilic asthma. N Engl J Med. 2014;371(13): 1198-1207.

54. Haldar P, Brightling CE, Singapuri A, et al. Outcomes after cessation of mepolizumab therapy in severe eosinophilic asthma: a 12-month follow-up analysis. J Allergy Clin Immunol. 2014;133(3):921-923.

55. GlaxoSmithKline. Efficacy and Safety Study of Mepolizumab Adjunctive Therapy in Participants with Severe Eosinophilic Asthma on Markers of Asthma Control; 2014. Available from: https://clinicaltrials.gov/ ct2/show/NCT02281318. Accessed June 1, 2015. [NLM Identifier: NCT02281318].

56. Liu Y, Zhang S, Li DW, Jiang SJ. Efficacy of anti-interleukin-5 therapy with mepolizumab in patients with asthma: a metaanalysis of randomized placebo-controlled trials. PLoS One. 2013; 8(3):e59872.

57. Nowak RM, Parker JM, Silverman RA, et al. A randomized trial of benralizumab, an antiinterleukin 5 receptor $\alpha$ monoclonal antibody, after acute asthma. Am J Emerg Med. 2015;33(1):14-20. 
58. Garrett JK, Jameson SC, Thomson B, et al. Anti-interleukin-5 (mepolizumab) therapy for hypereosinophilic syndromes. JAllergy Clin Immunol. 2004;113(1):115-119.

59. Rothenberg ME, Klion AD, Roufosse FE, et al. Mepolizumab HES Study Group. Treatment of patients with the hypereosinophilic syndrome with mepolizumab. N Engl J Med. 2008;20;358(12):1215-1228.

60. Leiferman KM. A role for eosinophils in atopic dermatitis. J Am Acad Dermatol. 2001;45(1):S21-S24.

61. Wedi B, Raap U, Lewrick H, Kapp A. Delayed eosinophil programmed cell death in vitro: a common feature of inhalant allergy and extrinsic and intrinsic atopic dermatitis. J Allergy Clin Immunol. 1997;100: 536-543.

62. Gnanakumaran G, Babu KS. Technology evaluation: mepolizumab, GlaxoSmithKline. Curr Opin Mol Ther. 2003;5(3):321-325.

63. Oldhoff JM, Darsow U, Werfel T, et al. Anti-IL-5 recombinant humanized monoclonal antibody (mepolizumab) for the treatment of atopic dermatitis. Allergy. 2005;60(5):693-696.

64. Moosig F, Gross WL, Herrmann K, Bremer JP, Hellmich B. Targeting interleukin-5 in refractory and relapsing Churg-Strauss syndrome. Ann Intern Med. 2011;155:341-343.

65. Kim S, Marigowda G, Oren E, Israel E, Wechsler ME. Mepolizumab as a steroid-sparing treatment option in patients with Churg-Strauss syndrome. J Allergy Clin Immunol. 2010;125(6):1336-1343.

66. Otani IM, Anilkumar AA, Newbury RO, et al. Anti-IL-5 therapy reduces mast cell and IL-9 cell numbers in pediatric patients with eosinophilic esophagitis. J Allergy Clin Immunol. 2013;131(6): 1576-1582.

67. Straumann A, Conus S, Grzonka P, et al. Anti-interleukin-5 antibody treatment (mepolizumab) in active eosinophilic oesophagitis: a randomised, placebo-controlled, double-blind trial. Gut. 2010;59: $21-30$.
68. Spergel JM, Rothenberg ME, Collins MH, et al. Reslizumab in children and adolescents with eosinophilic esophagitis: results of a double-blind, randomized, placebo-controlled trial. J Allergy Clin Immunol. 2012;129: 456-463.

69. Gevaert P, Van Bruaene N, Cattaert T, et al. Mepolizumab, a humanized anti-IL-5 mAb, as a treatment option for severe nasal polyposis. J Allergy Clin Immunol. 2011;128(5):989-995.

70. GlaxoSmithKline. Efficacy and Safety of Mepolizumab as an Add-On Treatment in Chronic Obstructive Pulmonary Disease (COPD); 2014. Available from: https:/clinicaltrials.gov/ct2/show/NCT02105961. Accessed May 26, 2015. [NLM Identifier: NCT02105961].

71. McMaster University. Mepolizumab in Chronic Obstructive Pulmonary Diseases (COPD) with Eosinophilic Bronchitis; 2011. Available from: https:/clinicaltrials.gov/ct2/show/NCT01463644. Accessed May 26, 2015. [NLM Identifier: NCT01463644].

72. Roufosse FE, Kahn JE, Gleich GJ, et al. Long-term safety of mepolizumab for the treatment of hypereosinophilic syndromes. JAllergy Clin Immunol. 2013;131(2):461-467.

73. Robinson DS. Mepolizumab treatment for asthma. Expert Opin Biol Ther. 2013;13(2):295-302.

74. Kikuchi S, Nagata M, Kikuchi I, Hagiwara K, Kanazawa M. Association between neutrophilic and eosinophilic inflammation in patients with severe persistent asthma. Int Arch Allergy Immunol. 2005;137(1): $7-11$

75. Menzella F, Facciolongo N, Piro R, et al. Clinical and pharmacoeconomic aspects of omalizumab: a 4-year follow-up. Ther Adv Respir Dis. 2012;6(2):87-95.

76. Cost a focus as GSK takes lead in new wave of biotech lung drugs. Reuters Edition UK. Mon September 8, 2014 1:45 pm BST. Available from: http://uk.reuters.com/article/2014/09/08/health-respiratory-gskidUKL5N0R921Y20140908. Accessed July 31, 2015.

\section{Publish your work in this journal}

The Journal of Asthma and Allergy is an international, peer-reviewed open-access journal publishing original research, reports, editorials and commentaries on the following topics: Asthma; Pulmonary physiology; Asthma related clinical health; Clinical immunology and the immunological basis of disease; Pharmacological interventions and

\section{Dovepress}

new therapies. Issues of patient safety and quality of care will also be considered. The manuscript management system is completely online and includes a very quick and fair peer-review system, which is all easy to use. Visit http://www.dovepress.com/testimonials.php to read real quotes from published authors. 